\title{
Effects of APC on Hydration and Microstructure of Portland Lime-Mud Cement
}

\author{
Lihua Zhang 1, 2, a, Yunshang Zhang1, b and Laibao Liu'1, 2, c
}

${ }^{1}$ Southeast University, Nanjing 211189, China;

${ }^{2}$ Southwest University of Science and Technology, Mianyang 621010, China.

azhanglihua1250@163.com, b zhangys279@163.com, cliulaibao@swust.edu.cn

Keywords: pulp mill lime mud, cement, grinding aids, hydration, microstructure.

\begin{abstract}
This Through the measurement of the hydration heat, the thermo analysis, SEM observation, and analysis on pore structure of the cement paste, we did the research on the effects of Alcamine Periodic Copolymer (APC) grinding aids on hydration and microstructure of Portland Lime-Mud Cement (PLMC). The result indicates that APC can significantly improve the strength of PLMC at ages. Within twelve hour hydration, APC surrounding cement particles slows down the hydration of $\mathrm{C}_{3} \mathrm{~S}$ and $\mathrm{C}_{3} \mathrm{~A}$, whereas accelerates the hydration in the later stages by lubricating when the surrounding layer is released after twelve hours. The air entrainment by APC broadens overall porosity distribution in the early stage of cement and SEM observation reveals many pores in the cement. In the later stages of hydration, the porosity ratio is decreased and SEM shows increased volumes of interleaved hydration products and denser cement structure.
\end{abstract}

\section{Introduction}

Lime Mud is muddy precipitated by-product produced by the causticizing reaction during the alkali recovery in the pulp mill. It is largely calcium carbonate (more than 90\%) and is the good choice as the cement admixture in the industry. With the tiny particle size, 45\% - 60\% moisture, and colloid properties, the lime mud is difficult to dry. Even though the lime mud gets dried completely, particles still tend to agglomerate together to form larger clusters resulting in uneven distribution. These are the fundamental constraints on the industrialization of the lime mud ${ }^{[1-3]}$.

Given this, our research team considered adding the lime mud directly in the cement mill cooling system and taking advantage of the heat released by the cooling process of hot clinker to dry the lime mud. The dried lime mud is mixed with the clinker directly. In order to solve the agglomeration issue after drying, we added a type of homemade composite grind aids at the same time when adding the lime mud. Thus, the modification of the lime mud and the preprocessing of clinker for facilitating grinding get completed at the same time. The experience of the industrial production suggests ${ }^{[4,5]}$ that modified lime mud can partially replace the fly ash or slag as the cement admixture for producing P.O42.5 cement. All physical properties meet the standard requirements. However, the further research has not been conducted on the effects of APC on hydration and microstructure of PLMC. Thus, this paper is to investigate such effects and provide the dependable theoretical basis for applying APC in PLMC.

\section{Experimental Details}

Portland lime mud cement (composed of $89 \%$ clinker, 5\% lime mud and 6\% natural gypsum, grinded by ball mill for $1 \mathrm{~h}$ ) was used. Clinker and natural gypsum are from Sichuan Esheng Cement Group Co.Ltd. Lime mud (dried by $105^{\circ} \mathrm{C}$ before test) is from An Xian Paper Manufacture Co.Ltd. The compositions of the materials are shown in Table 1. The grinding aid called Alcamine Periodic Copolymer (APC) is the composite organic one formed by the blockpolymerization of triisopropanolamine and the other two alcohols (triethanolamine and glycol). The goal of this paper is 
to discuss the effects of this grinding aid on hydration and microstructure of cement, so it is mixed as additive. Its effects as the grinding aids are not discussed in this paper.

Table 1 Chemistry compositions of main raw materials

\begin{tabular}{cccccccccccc}
\hline Material & Loss & $\mathrm{CaO}$ & $\mathrm{SiO} 2$ & $\mathrm{Al} 2 \mathrm{O} 3$ & $\mathrm{Fe} 2 \mathrm{O} 3$ & $\mathrm{MgO}$ & $\mathrm{SO} 3$ & $\mathrm{R} 2 \mathrm{O}$ & $\mathrm{P} 2 \mathrm{O} 5$ & moisture & $\mathrm{SUM}$ \\
\hline $\begin{array}{c}\text { Clinker } \\
\begin{array}{c}\text { White } \\
\text { mud }\end{array}\end{array}$ & - & 65.72 & 22.47 & 4.77 & 3.46 & 1.16 & 0.87 & 0.68 & 0.05 & - & 99.18 \\
$\begin{array}{c}\text { Dihydrate } \\
\text { gypsum }\end{array}$ & - & 41.64 & 5.5 & 0.85 & 0 & 7.39 & - & 1.92 & - & 54 & 99.47 \\
\hline
\end{tabular}

The mixing proportions for the experiments on cement paste are displayed in table 2. Sample A0 and $\mathrm{A} 4$ are the cement paste mixed with APC.

Table 2 Mixing proportions of cement paste and mortar with APC

\begin{tabular}{cccccc}
\hline \multirow{2}{*}{ Sample } & \multirow{2}{*}{ Mass fraction of APC/\% } & \multicolumn{3}{c}{ Mass/g } & \multirow{2}{*}{$\begin{array}{c}\text { Mass ratio of } \\
\text { water to cement }\end{array}$} \\
\cline { 3 - 5 } A0 & 0 & Cement & Water & Normal Sand & 0.35 \\
A1 & 0.02 & 1500 & 525 & 0 & 0.35 \\
A2 & 0.04 & 1500 & 525 & 0 & 0.35 \\
A3 & 0.06 & 1500 & 525 & 0 & 0.35 \\
A4 & 0.08 & 1500 & 525 & 0 & 0.35 \\
\hline
\end{tabular}

\section{Results and Discussion}

\subsection{Heat of Hydration}

There are generally three hydration heat peaks for Portland cement ${ }^{[6-8]}$ : The first peak is majorly from the dissolution of the active minerals and the formation of Aft. The second peak is mainly due to the formation of $\mathrm{C}-\mathrm{S}-\mathrm{H}$. If the gypsum depletes during the hydration, Aft will be transformed to Afm and result in the $3^{\text {rd }}$ peak after the $2^{\text {nd }}$ one. The figure 1 and 2 are the heat evolution rate of PLMC hydration and accumulated hydration heat, with or without APC respectively.
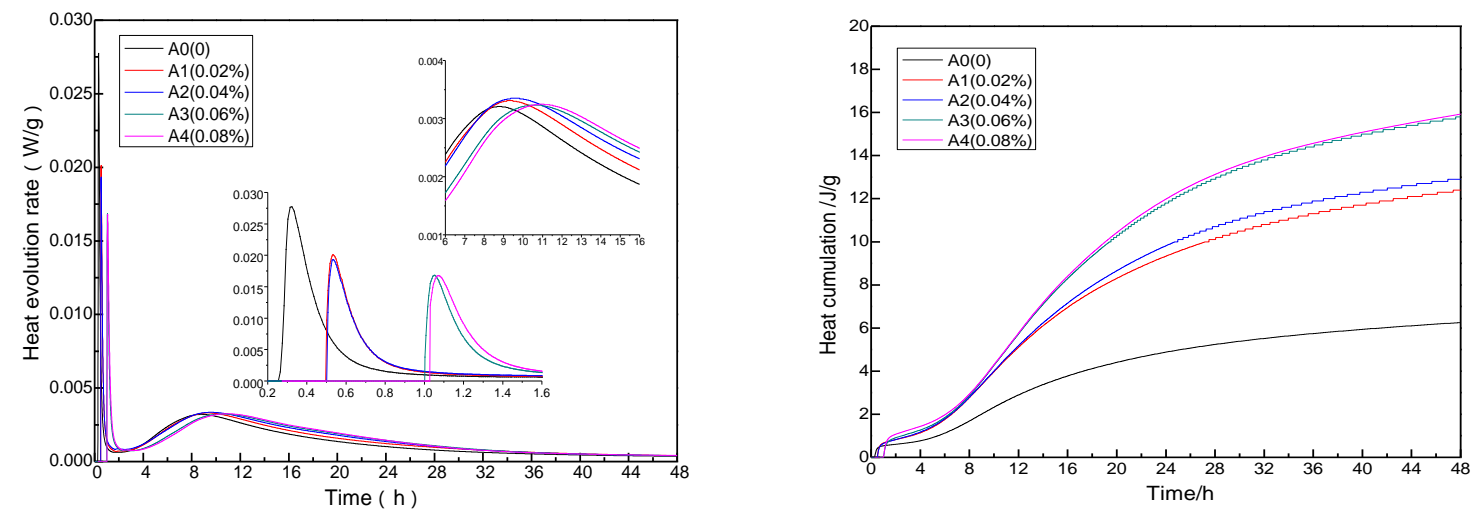

Fig.1 Heat evolution rate of hydration of PLMC with APC Fig.2 Cumulative heat of hydration of PLMC with APC

From Fig 1, the first peak decreases as the amount of APC mixture increases, and gets postponed. This indicates that APC has not affected the formation of Aft, as APC surrounding layer on the surface of the cement particles has not got the chance to release thus the water can not reach the particle surface rapidly. Such fact slows down the formation of Aft. Likewise, the $2^{\text {nd }}$ peak shows the similar pattern. That is, the $2^{\text {nd }}$ peak gets postponed and lowered slightly as the amount of APC increases, indicating that APC slightly affects the initial hydration of $\mathrm{C}_{3} \mathrm{~S}$. There is no $3^{\text {rd }}$ peak if the gypsum is adequate. The fig 2 shows that even though both the $1^{\text {st }}$ and $2^{\text {nd }}$ peak gets postponed, $48 \mathrm{~h}$ cumulative heat clearly 
increases with the increasing amount of APC, indicating that APC surrounding layer has been released completely and lubricating among cement particles and water, promoting the entire hydration process.

\subsection{Thermal Analysis}

The fig 3 and 4 are respectively $1 \mathrm{~d}$ and $28 \mathrm{~d}$ TG and DSC curves for sample A0 and A4 in the strength experiments. The sample has been vacuum dried, so there is not free water. According to literatures ${ }^{[9-11]}$ : among the hydration products, the dehydration temperature of Aft is between $130-180{ }^{\circ} \mathrm{C}$; the decomposition temperature of $\mathrm{Ca}(\mathrm{OH})_{2}$ is between $430{ }^{\circ} \mathrm{C}$ and $450{ }^{\circ} \mathrm{C}$; the decomposition temperature of $\mathrm{CaCO}_{3}$ is between $700^{\circ} \mathrm{C}$ and $740^{\circ} \mathrm{C}$. Because the heating rate $\left(10^{\circ} \mathrm{C}\right.$ $/ \mathrm{min}$ ) is high in the experiment, the corresponding decomposition temperature on the curves deviates to some degree. Comparing Fig3 to Fig4, we know that the peak of $110^{\circ} \mathrm{C}-120^{\circ} \mathrm{C}$ was caused by the dehydration of $\mathrm{Aft} ; 470^{\circ} \mathrm{C}-490^{\circ} \mathrm{C}$ by the decomposition temperature of $\mathrm{Ca}(\mathrm{OH})_{2} ; 740{ }^{\circ} \mathrm{C}-850^{\circ} \mathrm{C}$ by the decomposition of $\mathrm{CaCO}_{3}$.
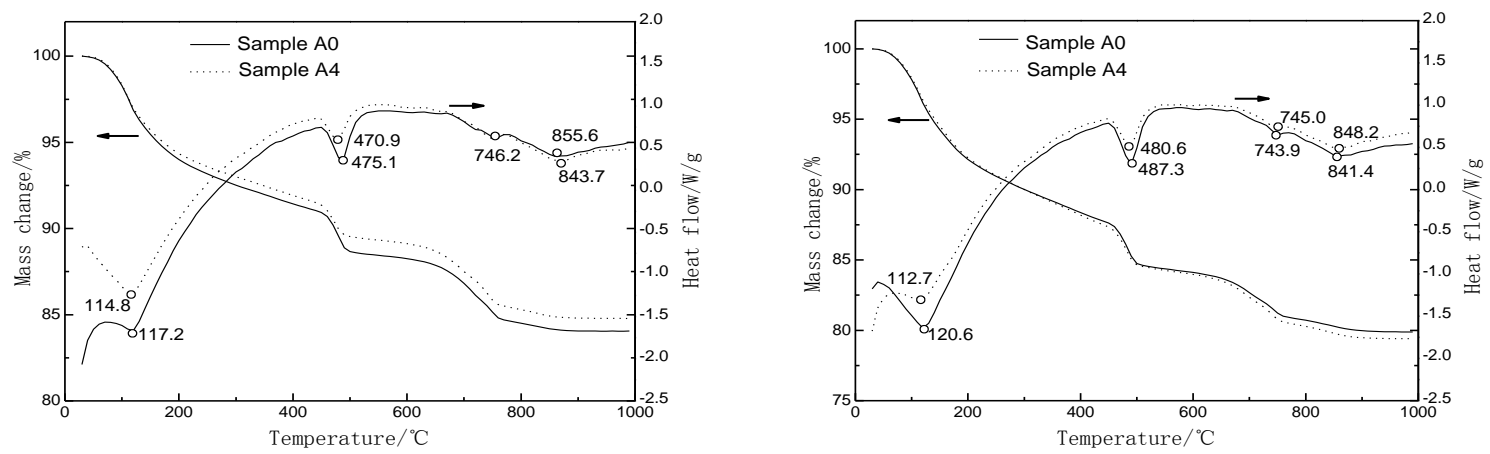

Fig. 3 Thermal analysis of pastes hydrated for $1 \mathrm{~d}$ Fig. 4 Thermal analysis of pastes hydrated for $28 \mathrm{~d}$

In order to facilitate comparing the amount of $\mathrm{Ca}(\mathrm{OH})_{2}, \mathrm{CaCO}_{3}$ and the change in the hydration products of the sample A 0 and $\mathrm{A} 4$, we calculated the relative contents of hydration products according to the thermal gravimetric loss of the corresponding temperature range on the thermal gravimetric curves and showed the result as Table 3 . We see that $\mathrm{Ca}(\mathrm{OH})_{2}$ content in the sample A0 and A4 increases as the age increases. However, the contents of $\mathrm{Ca}(\mathrm{OH})_{2}$ in $\mathrm{A} 0$ and $\mathrm{A} 4$ of the same age are close. At $1 \mathrm{~d}, \mathrm{~A} 4$ is less than $\mathrm{A} 0$ by $0.62 \%$; at $28 \mathrm{~d}$, A4 is more than $\mathrm{A} 0$ by $0.2 \%$. Because $\mathrm{Ca}(\mathrm{OH})_{2}$ is majorly formed by $\mathrm{C}_{3} \mathrm{~S}$ hydration, mixing APC does not promote the hydration of $\mathrm{C}_{3} \mathrm{~S}$ in the early stages, and does not affect the hydration at the later stages significantly. Taking both hydration heat and strength analysis into account, we see the major effects of APC on cement hydration: at the early stages of hydration, APC forms the organic surrounding layer on the surface of cement and lime mud particles. Even though slowing down the hydration of hydration products, it promotes the lubrication among the particles, improves the spatial distribution. Moreover, it gets released in the short time, so does not affect the development of cement strength at the early stages.

Table 3 Relative contents to unhydrated cement for $\mathrm{Ca}(\mathrm{OH}) 2$ and $\mathrm{CaCO} 3$

\begin{tabular}{cccc}
\hline Sample & Age/d & w $[\mathrm{Ca}(\mathrm{OH}) 2] / \%$ & $\mathrm{w}[\mathrm{CaCO} 3] / \%$ \\
\hline A0 & 1 & 2.84 & 3.68 \\
A0 & 28 & 3.38 & 3.40 \\
A4 & 1 & 2.22 & 3.66 \\
A4 & 28 & 3.58 & 3.68 \\
\hline
\end{tabular}

\subsection{SEM Investigation}

From Fig5, there are plenty of gaps in the cement stone within $3 \mathrm{~d}$ hydration of A0, and the surface is covered by the unreacted lime mud particles. The cotton-shaped C-S-H gel, flaky $\mathrm{Ca}(\mathrm{OH})_{2} \mathrm{crystal}$, and columnar Aft appear in $3 \mathrm{~d}$ cement stone. In $28 \mathrm{~d}$ cement stone, the hydration products increase significantly, and the structure becomes denser without evident gaps. Compared to A0 at the same age, 
the structure of A4 cement stone is relatively denser, and evident gaps and the coverage of lime mud are relatively less. Moreover, we see the hydration products like C-S-H gel, $\mathrm{Ca}(\mathrm{OH})_{2}$, and Aft in $28 \mathrm{~d}$ cement stone, which are interleaved with each other to form the denser structure.
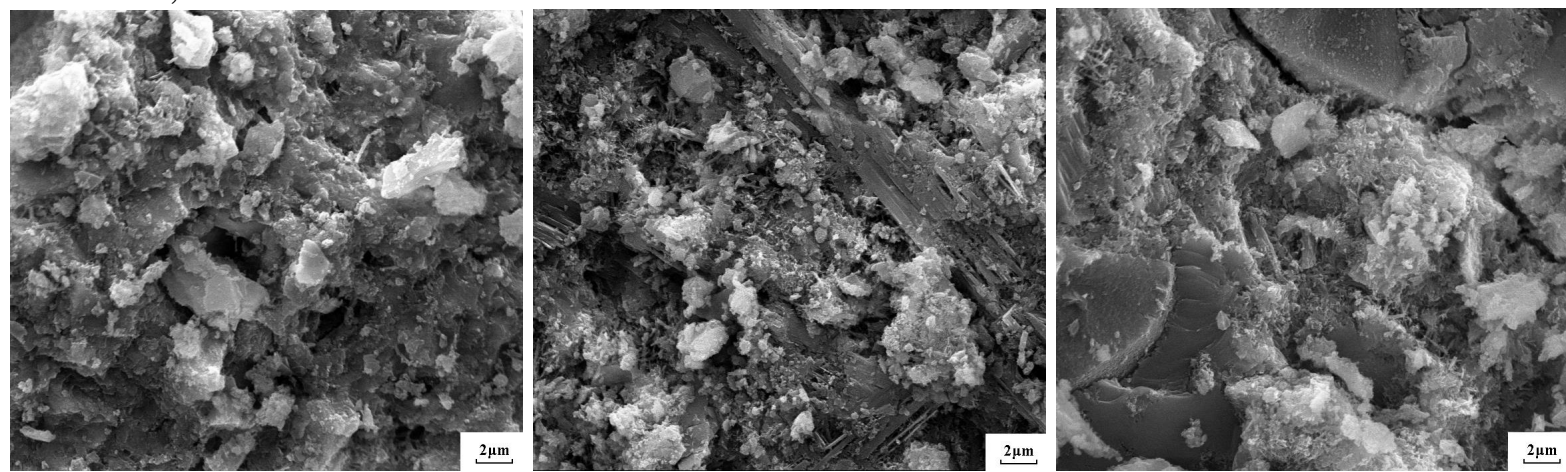

(a)Hydration of sample A0 for 1d (b) Hydration of sample A0 for 3d (c) Hydration of sample A0 for 28d
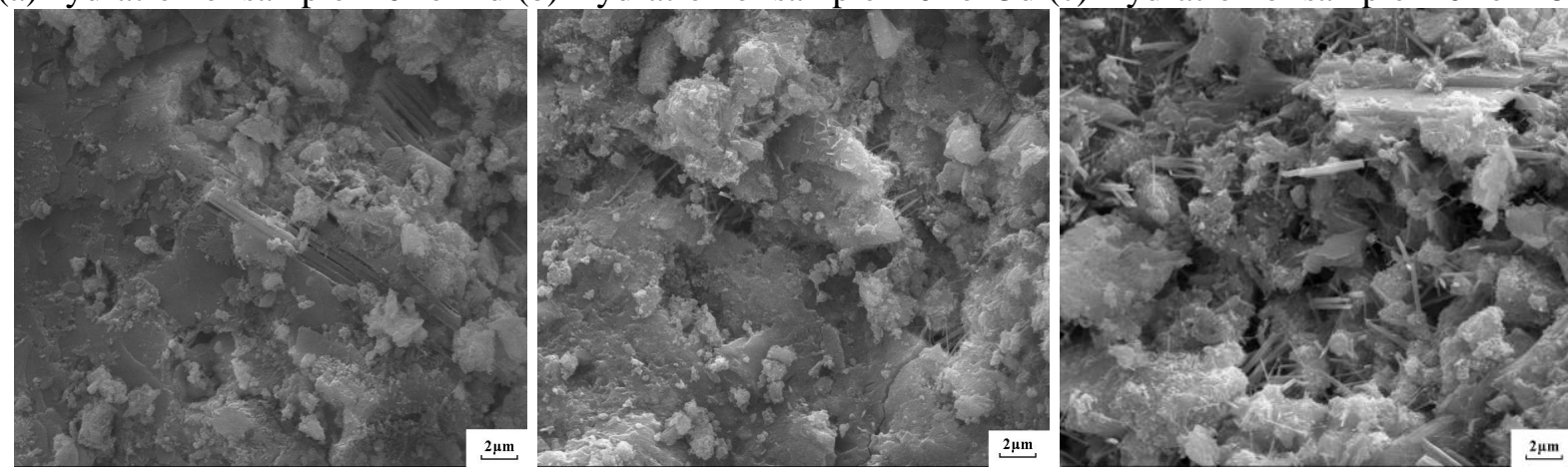

(d)Hydration of sample A4 for 1d (e) Hydration of sample A4 for 3d (f) Hydration of sample A4 for 28d

Fig.5 SEM of samples A0 and A4 at different ages

\subsection{Pore Strucure}

To analyze the effect of APC on the pattern of porosity structure of PLMC paste, we selected A0 and A4 with 1d and 28d hydration. The porosity distribution is shown in fig 6. Table 4 lists the properties of pore structure of hardened cement.

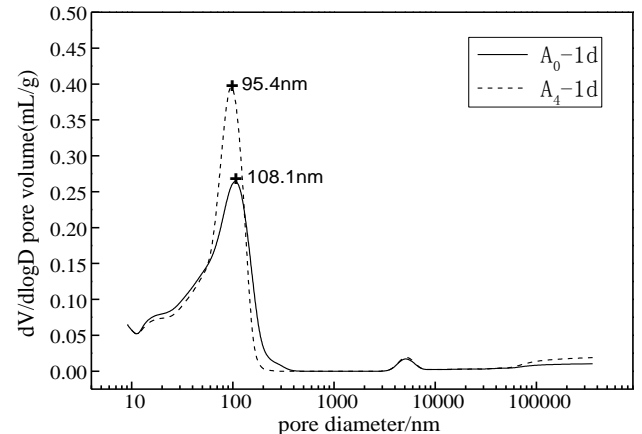

(a)Samples A0 and A4 for 1d

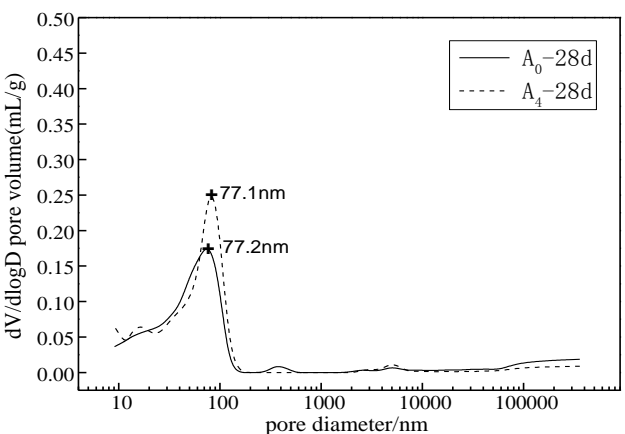

(b) Samples A0 and A4 for 28d

Fig.6 Pore size distribution of samples A0 and A4 hydrated for 1d and 28d

Tab.4 Pore structure parameters of cement pastes at different ages

\begin{tabular}{|c|c|c|c|c|c|c|c|c|}
\hline \multirow[b]{2}{*}{ Sample } & \multirow[b]{2}{*}{ Age/d } & \multirow{2}{*}{$\begin{array}{c}\text { Total } \\
\text { porosity } / \%\end{array}$} & \multirow[b]{2}{*}{$\begin{array}{l}\text { Average pore } \\
\text { diameter/nm }\end{array}$} & \multirow{2}{*}{$\begin{array}{l}\text { Median pore } \\
\text { diameter/nm }\end{array}$} & \multicolumn{4}{|c|}{ Pore size distribution $/ \%$} \\
\hline & & & & & $3.5-10 \mathrm{~nm}$ & $10-50 \mathrm{~nm}$ & $50-1000 \mathrm{~nm}$ & $\begin{array}{c}> \\
1000 \mathrm{~nm}\end{array}$ \\
\hline A0 & 1 & 32.98 & 38.7 & 20.2 & 7.29 & 29.89 & 58.62 & 4.20 \\
\hline A0 & 28 & 23.79 & 37.2 & 19.0 & 5.37 & 32.84 & 54.36 & 7.43 \\
\hline A4 & 1 & 34.86 & 41.5 & 20.7 & 6.94 & 26.36 & 61.83 & 4.88 \\
\hline A4 & 28 & 21.74 & 33.1 & 16.6 & 9.28 & 37.63 & 46.68 & 4.41 \\
\hline
\end{tabular}


Fig.6 is marked with the critical pore diameter in sample, which refers to the diameter of the connected pore allowing maximum materials permeating through the cement stone, and reflects the connectivity of gaps and tortuosity of permeating paths in the cement stone ${ }^{[12]}$. From fig 6 and table 4, we see that the critical pore diameter of $\mathrm{A} 4$ is smaller than $\mathrm{A} 0$ by $12.7 \mathrm{~nm}$ at $1 \mathrm{~d}$, whereas the overall porosity of A4 is larger than A0 by $1.88 \%$, average pore diameter larger by $2.8 \mathrm{~nm}$, median pore diameter larger by $0.5 \mathrm{~nm}$, and the ratio of large pores $(>50 \mathrm{~nm})$ in A4 is greater than A0. This indicates that at the early stages of hydration, APC makes the cement particles redistribute spatially and the number of connected pores in paste decrease. Due to the air entrainment by APC, however, large amount of bubbles got generated. There are not enough hydration products for filling up gaps at this moment, so the distribution range of overall porosity becomes wide. At $28 \mathrm{~d}$, the difference between their critical pore diameter is only $0.1 \mathrm{~nm}$, the overall porosity of A4 is smaller than A0 by $2.05 \%$, average pore diameter smaller by $4.1 \mathrm{~nm}$, and the median pore diameter smaller by $2.4 \mathrm{~nm}$. Moreover, the ratio of small pores $(<50 \mathrm{~nm})$ in A4 is much greater than A0, indicating that large pores, introduced by APC organic ingredient at the early stages, are being gradually filled up with hydration products, as the hydration reaction is going on. The spatial redistribution of cement particles played a great role in the later stages of hydration, making hydration products interleaved and distributed evenly, improving the structure of cement stone.

\section{Conclusion}

Within twelve hour hydration, APC forms the organic surrounding layer on the surface of cement and lime mud particles, slowing down the hydration of $\mathrm{C}_{3} \mathrm{~S}$ and $\mathrm{C}_{3} \mathrm{~A}$, so there are no large amount of hydration products formed in the cement stone. However, the organic surrounding layer gets releases after $12 \mathrm{~h}$, lubricates between cement particles and water, promotes the rheology and fluidity, improves the internal distribution, thus accelerates the hydration at the later stages. The air entrainment by organic APC ingredients generates large amount of bubbles in the cement stone in the early stages of hydration and makes the overall porosity distributed widely. SEM observation reveals many gaps. In the later stages of hydration, the ratio of small pores increases and the number of large pore decreases. The large pores introduced early get filled up by hydration products and the overall porosity decreases. SEM shows increased volumes of interleaved hydration products and denser cement structure.

\section{Acknowledgments}

The authors gratefully acknowledge support from the National Basic Research Program (973) of China (No. 2015CB6551002) and the National Natural Science Foundation of China (No. 51378116).

\section{References}

[1]. Zhang Bolian, Feng Qiming, Luo Huigang. Production Pocess of Brick by Uing White Mud of Paper Industry and Shale as Raw Materials[J], China pulp \& paper, 2011,30 (1): 33-36.

[2]. Zhu Maoxu, Li Lee, Wang Haihua, Wang Zheng. Removal of an anionic dye by adsorption/precipitation processes using alkaline white mud [J], Journal of Hazardous Materials, 2007, 149(3):735-741.

[3]. Zhang Guochen, Li Xia, Li Yujiang. Removal of anionic dyes from aqueous solution by leaching solutions of white mud [J]. Desalination, 2011, 274(1):255-261.

[4]. Liu Laibao, Tang Kaijing, Zhang Lihua. Experimental study on white cement using lime mud as admixture[J]. Cement, 2014, 1: 7-9.

[5]. Liu Laibao, Zhang Lihua, Zhang Lihua, Zheng Aizhong. Zhou Yongsheng. A modification method of waste lime mud and one-step cement technology for cement admixture[P].China:201310172584.6,2013.05.10

[6]. KUMAR MEHTA P, MONTEIRO P J M. Concrete Microstructure, Properties, and Materials [M].The United States of America: McGraw-Hill Professional, 2005. 
[7]. SHI Huisheng. The Civil Engineering Material: Performance, Application and Ecological Environment (in Chinese). Beijing: China Power Press, 2008:49-51.

[8]. LI Jianli. Cement Crafts (in Chinese). Wuhan: Wuhan University of Technology Press, 1999: 207-210.

[9]. Xiao Jia. The Study on Characteristics of Cement-ground Limestone Gelation System[D]. Changsha: Central South University, 2008:69-83.

[10]. Yang Dingyi, Sun Wei, Liu Zhiyong. THERMAL DECOMPOSITION KINETICS OF ETTRINGITE CRYSTAL[J]. JOURNAL OF THE CHINESE CERAMIC SOCIETY, 2007,35(12):1641-1645.

[11]. Sha W, Pereira G B. Differential scanning calorimetry study of ordinary Portland cement paste containing metakaolin and theoretical approach of metakaplin acticity [J]. Cem. Concr. Res, 2001,23:455-461.

[12]. Wan Huiwen, Yang Shuyan, Lv Yangfeng. Resistance to Chloride Ion Penetration and Properties of Pore Structure in Air-Entraining Concrete[J], Journal of building materials, 2008, 11(4): 409-413. 